Citation: Chapter 42: Mobile Learning and Games in Special Education

Penny Standen \& David Brown

In: The SAGE Handbook of Special Education: Two Volume Set

Edited by: Lani Florian

DOI: http://dx.doi.org/10.4135/9781446282236.n44

Subject: Special \& Inclusive Education (general)

\title{
Mobile learning and games in special education (5500 words)
}

\section{Introduction}

Information technology is now a ubiquitous presence in all educational settings as well as places in which people work. While most mainstream schools now rely heavily on this technology to support learning, special education was often at the forefront of its adoption even acting as exemplars for mainstream education (Lilley, 2004). Educational virtual environments had been developed in special schools and adult training centres when virtual reality was still a novel technology in education (Standen \& Brown, 2004; 2005; 2006). Now no school or educational setting would be imagined without information technology and there have been some exciting developments since those early pioneering days. In this chapter we intend to cover three of those which we think are particularly pertinent for learners with special needs: serious games, mobile computing and the role of users in the development of the technology.

\section{The role of games in education and training}

A recent development in educational software is to recognise the value of learning through playing computer or video games. For a recent review see Ulicsak and Wright (2010). The term "serious game" has been coined to refer to a game designed for a primary purpose other than pure entertainment. While the purpose of the game could be serious such as learning a complex concept or a skill, the qualities associated with games are intended to enhance this learning. Although games do not have to be electronic, the majority of the material available on serious games refers to computer or video games. Earlier work on computer games tended to focus on the negative aspects (Elgi \& Meyers, 1984) an observation echoed by Williamson (2009): "Games have become a major recreational activity, sometimes considered - especially in the tabloid and conservative press - to be culturally degenerate" (p. 9). Williamson went on to say "yet they have also become increasingly sophisticated and celebrated as a cultural form; they have shaken up the world of entertainment, and they have entered into educational debates and practices" (p. 9). Play and games had been recognised as having an important role in early learning, but Pivec (2007) makes the point that, as education becomes more formal, games tend to be seen as just an "unserious activity" (p. 387). 
More recently the positive aspects of games in formal education have been explored whether this involves using commercially produced games or bespoke educational games that are designed to be as engaging as commercial, entertainment games but intended to have an educational outcome.

For learners with special needs, whatever their age, the engaging nature of computer games is what makes them an ideal addition to the learning toolkit. Pivec (2007) highlights the ability of games to engage the learner voluntarily in sufficient repetitions of the activities to ensure learning takes place (Pivec, 2007). This is what Garris, Ahlers and Driskell (2002) termed persistent reengagement, where the player returns to the task unprompted. The motivational power of computer game playing was demonstrated in a study by Standen, Brown, Anderton \& Battersby (2006a) to design a new navigational interface for virtual environments for people with intellectual disabilities. The users in this study needed to use the device regularly over a period of eighteen months in order to complete a baseline evaluation and to test each version of the prototype. This was easily achieved by allowing them to play computer games specifically designed for the study.

A second characteristic to be exploited in serious games is the immediate feedback they can provide so that an activity is easily linked with a learning outcome, in Pivec's (2007) words: "the debriefing process between the game cycle and the achievement of the learning outcomes" (p. 388). Finally, games can be structured with different levels of challenge which makes them flexible enough to appeal to users with a wide range of ability or skill and to learners from their first attempt through to increasing levels of familiarity. They can thus be used to provide scaffolding for new learners by, for example, controlling those elements of the task that are initially beyond the beginner's capability. As the beginner becomes more familiar with elements of the task and develops the ability to carry it out independently the scaffolding can be removed. The secret is to ensure a balance between success and challenge and the different levels that can be built into games provide this. These characteristics of games were the reasons Sik Lányi, Brown, Standen, Lewis, and Butkute (2010) designed computer games to teach employment skills to young people with intellectual disabilities. Similarly, Savidis, Grammenos, and Stephanidis (2007) designed two computer games for people with intellectual disabilities in Crete to help their users acquire employment skills. They hoped that by supplementing these with two accessible and highly configurable remakes of the classic space invaders and the pong arcade games, they would not only motivate the learners but improve their basic kinaesthetic skills, orientation capabilities, short term strategic thinking, decision making and self esteem. Exposing learners to the games as well as the two training applications was intended to have an amplifying effect and support faster learning cycles.

There is an increasing amount of evidence in the wider population for positive effects of computer game playing on cognitive and perceptual skills. Green and Bavelier (2003) found that playing action video games can give a person the ability to monitor more objects in their visual field and do so faster than a person who does not play such games. In a later study, Green and Bavelier (2007) found a causative relationship between action video game playing and increased spatial resolution of visual processing. In order to explore whether game playing might have benefits for people with intellectual disabilities, Standen, Brown, Anderton, and Battersby (2006b) assessed the effect of playing a switch controlled computer game with a time limit for responses on choice reaction time. They found a significant decrease in choice reaction time in the intervention group compared to the control group who, for the same amount of time, played a game with no time limit. In a later study, Standen, Rees and Brown (2009) investigated whether computer games may give people with 
intellectual disabilities the opportunity to practice the underlying components of decision making, a skill in which they can experience difficulties. After repeated sessions playing a Tetris like game, the intervention group showed a significant improvement in two paper based tests of decision making. The decrease observed in the control group failed to reach significance. Using a version of the same game, this time requiring players to focus on fractions and percentages Brown, Ley, Evett and Staden (2011) observed an improvement in the understanding of fractions in school aged students with intellectual disabilities after several sessions playing the game when compared to a control group. There is also encouraging evidence that memory skills of young people with intellectual disabilities can be enhanced through game playing (Brown, Mclver, Standen, \& Dixon, 2008; Van der Molen, Van Luit, Van der Molen, Klugkist, \& Jongmans, 2010).

In addition to teaching basic skills and improving cognitive and perceptual abilities, games have been successfully employed to enhance social interaction in young people with autism. The Collaborative

Puzzle Game was initially used by Battocchi et al. (2010) to study social interactions among boys with Autistic Spectrum Disorder (ASD) and those with typical development as well as testing the system as a rehabilitative tool. This tabletop game promotes collaboration since, in order to be moved, digital puzzle pieces must be touched and dragged simultaneously by the two players. Actions on digital objects can be performed only through the simultaneous touch of two or more users. For children with ASD, the game was effective in triggering behaviours associated with co-ordination of the task and negotiation.

The exploration of the potential of serious games is still in its infancy. Thus, the challenge for educators who might wish their students to benefit from these developments is that the availability of suitable games for their students is severely limited. The work reviewed above was largely carried out by researchers whose games were produced in house and, if distributed, lack any form of continuing support or updating. In the absence of any commercially available games that have been shown to be beneficial for children with special needs it is worth checking websites such as http://www.futurelab.org.uk and http://www.do2learn.com http://www.brighthubeducation.com that either advise on recent developments and evaluations or provide free resources http://www.bbc.co.uk/cbeebies. The games used in our research projects are available for free download from http://isrg.org.uk/projects/

\section{Mobile computing/learning}

Much of the earlier employment of information technology in special education depended on desktop computers. While these still have a huge role in education and entertainment especially for the experience of three dimensional virtual environments, advances in technology have meant that the inevitable progression in miniaturisation has allowed individuals to carry their computing power around with them. This has resulted in the use of laptops, notebooks and personal digital assistants (PDAs). For young people especially, the must have device is a smart phone which has advanced computing ability and connectivity. It can be used as a portable media player and camera, may have a high-resolution touchscreen, web browser, GPS navigation, Wi-Fi and mobile broadband access. Learners with special needs recognise the significance of this particular technology and the status it carries with their peers. While handheld devices can pose serious challenges for some learners with disabilities especially if they have poor vision or dexterity, these devices are already being used in the classroom. 
One of the first uses of mobile devices was in prompting individuals to complete everyday tasks particularly for individuals with autism (e.g. Gentry, Wallace, Kvarfordt, \& Lynch, 2010). However, this approach does not always involve hands on use by the learner themselves. As part of a programme to improve employability, Burke, Andersen, Bowen, Howard, and Allen (2010) adapted a standard iPhone application to provide performance cues to teach fire safety to six young adults on the Autism Spectrum. The cues were displayed on an iPod which assistants controlled using an iPhone. Although a small study, the system appeared to be effective and received high satisfaction ratings from both learners and their parents.

Mobile devices also lend themselves to supporting communication. Rodríguez-Fórtiz et al. (2009) developed an augmentative and alternative communication application for mobile devices to enable students with severe communication disorders to participate in instructional activities alongside their non-disabled peers. Van der Meer and colleagues (2011) have been using the iPod as a communication device for individuals with developmental disabilities who lack speech. They successfully taught two of their three participants to request snacks and toys by selecting graphic symbols on an iPod Touch.

An exciting development for mobile devices has been to support learning in any environment the learner chooses. While desktop computing limited the delivery of material to a particular indoor location, with a mobile device learning can be undertaken precisely in the context in which it is to be used with a close relationship between the learning experience and the situation in which the learning need arises (Naismith, Lonsdale, Vavoula, \& Sharples, 2004). Ensuring that learning takes place in a context similar to that in which it is required is particularly important for a target audience described as 'concrete thinkers' whose performance is characterised as rigid, context dependent or as blind rule following and for whom generalisation of learnt skills from one setting to another is unreliable (Gow, Balla, \& Butterfield, 1990). Moving the environment of learning to a real world and real time context might also help to compensate for the poor memory skills often associated with this target audience (Burack \& Zigler, 1990). Recognising the social dimension of learning, students may perform the exercises cooperatively with peers who may be in diverse physical locations and classroom teaching can be complemented through facilitating the participation of families. This was the intention behind the development of the virtual learning environment described by Fernández López, Rodríguez Fórtiz, and Noguera (2009) which is further discussed below. These researchers planned to facilitate the participation of families and professionals during the learning process by enabling their environment to run on both the iPod touch and iPhone device.

Schelhowe and Zare (2009) created a mobile application for people with mild to severe intellectual disabilities which could be personalised to an individual's profile by downloading learning materials from a server. This approach was also taken by Fernández López et al. (2009) who created a platform for learning materials for display on the iPod touch, iPhone and iPad for users with special needs. They describe three learning activities: Association, Puzzle and Exploration which could be personalised and played individually or cooperatively but learners would only interact with those activities that the teachers decided should be presented to them. No evaluation was reported on either of these two systems. However Nordness, Haverkost and Volberding (2011) report some preliminary results from a maths application for a hand-held computing device. They found an improvement in the subtraction skills of three individual second grade students with learning and behavioral disabilities. 
An added feature of smartphones is their ability to present information to the user based on their geographical position: location based services. This can be used to provide travel training for users with intellectual disabilities, to prompt them to execute location dependent tasks and to provide them with the appropriate information for carrying out the tasks, for example buying a sandwich at a shop. One of the core skills required for leading an independent life, social inclusion and accessing the world of work is the gaining of independent travel skills and having the confidence to learn and travel new routes. Of the unmet needs frequently reported by young disabled people and their families is practical support, advice and information on mobility (Clark \& Hirst, 1989).

Brown, McHugh, Standen, Evett, Shopland and Battersby (2010) developed an accessible location based device (RouteMate) based on the Android Operating System from Google to help people with intellectual disabilities plan and rehearse new routes to work, leisure and learning opportunities and then to carry these out independently in a safe manner. Mobile route guidance systems are in common use by vehicle drivers and have formed the basis of systems used in research projects to aid route following (e.g. Lemoncello, Sohlberg, \& Fickas, 2010). However, although such systems obviously reduce the mental load for drivers, their use suppresses the development of cognitive or mental maps. These are important for users with disabilities as conventional route guidance does not help when the traveller gets lost and wants to get back on track or just wants to get back to the starting point (Lindström, 2007). Thus RouteMate was designed to promote route learning rather than provide route guidance and thus facilitate the development of cognitive maps.

Because of its ability to locate the position of the user, the device can track the user's performance on previously trained routes and can indicate significant divergence from the planned route in terms of time or distance. This has two advantages. First of all, this can trigger an alarm to the user and then offer advice for correction. However, it can also automatically text the user's GPS position with a street name to a nominated other's mobile device, or call a nominated helper to help them conversationally to navigate to safety. Parents and caregivers of young people with intellectual disabilities, conscious of the widening gap between their child's capabilities and those of their nondisabled peers, feel they need to protect their child for longer and do not feel able to allow them the degree of independence allowed to their other children. For them, the possibility of receiving an alarm allows them the option of taking remedial action perhaps by giving advice over the phone to navigate to safety. Users with disabilities often stress the importance of having some way to locate themselves when they can no longer orientate themselves during a journey (Lindström, 2007). It was hoped that this facility might lead parents and carers to feel that they could allow the person in their care a greater degree of independence.

RouteMate http://recall-project.eu/ was developed in response to feedback from carers and young people with intellectual disabilities who took part in an earlier European funded project http://goetproject.eu/ aimed at helping young people with intellectual disabilities live more independently. There was much enthusiasm for the idea of developing such a device and in a subsequent project a prototype device was distributed to centres in four different European countries, Bulgaria, Greece, Romania and UK, for evaluation prior to further development. The centres included schools and training establishments specifically for those with disabilities. As part of this evaluation, researchers collected information on the attitudes of the young people with intellectual disabilities, their parents, trainers and therapists towards developing their ability to travel independently. The 
majority of young people with disabilities were very keen to be able to travel independently and welcomed the assistance that would be offered by a fully functioning system such as RouteMate.

However, trainers and carers, although acknowledging that travel training was a prerequisite for greater social inclusion, were a little less enthusiastic regarding independent travel. This difference of opinion is not surprising as what adolescents think is appropriate usually differs from what older adults like and while for the young person with disabilities RouteMate might offer a chance of independence, family members will be more concerned with practicality (Parette and Scherer, 2004). One of the major reasons they gave was the physical environment: the limited accessibility of buildings and public places; pavements being nonexistent, obstructed by parked vehicles or impassable due to lack of repair and the difficulty of crossing the road in urban areas. While the device would support finding one's way, the lack of road safety awareness would put them in danger. Interestingly, the device itself also presented risks. Carers feared that the phone on which RouteMate was running would be attractive to muggers. Finally, young people were thought to be more exposed to bullying and abuse if they were travelling independently. Earlier studies had shown considerable enthusiasm for support for independent travel. Why was this reluctance being voiced?

A consideration of this illustrates the issues that need to be taken into account with any development aimed to improve independence of young people with intellectual disabilities. The apparent contradiction voiced by parents and carers can be understood in terms of the view of risk described by Alaszewski \& Alaszewski (2002). These authors write that the "precise definition of risk is contested, with risk being equated at one extreme with danger and hazard, and therefore, being seen as something that should be avoided, while at the other, it is linked to personal development as a positive liberating experience" (p. 56). Parents and carers are faced on the one hand with current policy to facilitate increasing independence and the emphasis on young people's rights to autonomy and self-determination. On the other hand they are responsible for keeping them safe and they know the risks: travel risks were raised by parents in the study by Almack, Clegg and Murphy (2009) and people with intellectual disabilities experience a higher risk of serious pedestrian accidents, falls, fire and drowning (Strauss, Shavelle, Anderson, \& Baumeister, 1998). In the words of Almack et al. (2009) the challenge for these carers is having to "navigate complex boundaries between being seen to be over-protective and allowing these young people the autonomy to negotiate risk".

Although this note of caution has been introduced, there is already sufficient work to recommend the use of mobile devices. Apps for both iPhone and Android phones are increasingly available and many are free. Apps are appearing constantly and some sites actually recommend their apps for children with special needs e.g. http://www.childrenwithspecialneeds.com/index.php/specialneeds-apps.html and http://www.oneplaceforspecialneeds.com/main/library special needs apps.html

\section{User involvement in design}


The fears expressed by parents and carers in the development of RouteMate show just how important it is to take users'and their gatekeepers' views into account in the design process. Lack of consideration of user opinion in selection has been discovered to be an important factor in the abandonment of assistive devices (Kintsch \& De Paula, 2002), an outcome that can be an excessive financial cost for both services and families. Consumers also proffer the stigma associated with assistive devices as a reason for abandoning them (Parette $\&$ Scherer, 2004). A device such as a cane or wheelchair can be a visible sign that the person is vulnerable and makes them a target for theft or bullying. For some, the use of the device emphasises the difference between them and others and the absence of abilities. If they then decline to use the device their participation in society is limited not just by physical but also social barriers. As well as the visibility resulting from use of assistive technology in public settings, Parette and Scherer (2004) identified other issues in addition to stigma which could explain abandonment: family expectations of the technology and perceptions that children will not attain important developmental skills if they become reliant on devices.

In answer to some of these issues there has been a movement towards involving users in the design of assistive technology borrowing from paradigms such as "Design for all" (Horton, 2006), Universal Design for Learning" (Rose \& Strangman, 2007) and "Equitable Use". At its best, this involvement is actually driven by the users themselves as exemplified by organisations such as Devices for Dignity (www.devicesfordignity.org.uk) and Enabled by Design http://enabledbydesign.org/ . Buhler (2001) describes the successful involvement of users with disabilities in European R\&D projects and notes the advantages of such an approach in achieving the best end product.

The involvement of users with intellectual disabilities lags behind. However, the imperative to involve them in the design of assistive products is just as strong. Aware of the advantages of user involvement, researchers have endeavoured to involve users with intellectual disabilities in the design of input devices (Brown, Battersby, Standen, \& Anderton, 2005; Standen \& Brown, 2006) and software (Brown, Battersby, \& Shopland, 2005; Savidis et al., 2007; Brown, Standen, \& Evett, 2010). This has been successfully achieved while still adhering to established guidelines on user-centred design such as INUSE (Daly-Jones, Bevan, \& Thomas, 1999), USERfit (Poulson \& Waddell, 2001) and RESPECT (Maguire, Kirakowski, \& Vereker, 1998) https://dspace.lboro.ac.uk/dspacejspui/handle/2134/2651

An important first step as proposed by Buhler (2001) is to recognise that users in this context are not just the teachers, parents, carers, therapists or potential employers, who are usually the users whose opinions are sought, but the people with intellectual disabilities themselves and efforts need to be made to ensure their involvement is first hand with involvement by proxy kept to a minimum. Most of the processes described by Maguire et al. (1998) for evaluation of prototypes can be adapted satisfactorily by using computer generated virtual experiences as well as direct observation. So, a consolidated set of design requirements can be derived through observation of use of currently available devices or software rather than through seeking verbal feedback. Involvement in producing concept designs and prototypes can be achieved through storyboarding with an emphasis on pictorial representation and the use of multimedia and computer assisted design software to give users an approximation of what a prototype may look like. These approaches reduce the reliance on language and memory load. 


\section{Conclusions}

It is clear from reviewing current literature that special need education is keeping abreast of new technological developments but developers need to be braver about involving users in the design of applications. While the literature has been reviewed in three separate strands, some initiatives reviewed combine both games and mobile learning. In fact the initiatives by Brown et al. (2010) and Fernández López et al. (2009) both used a games based approach on a mobile device and were designed in conjunction with users with the potential for personalisation. Bearing in mind the problems of abandonment of devices, users and their carers have strong views on the adoption of devices and hopefully their views will be taken into account in future. There are enough examples now in the literature to enable this to happen. Designers wishing to see their developments adopted might also need to think about providing follow up support, something commercial organisations have had to do but independent researchers like the authors of studies reviewed here, do not have the resources to provide.

Perhaps the most disappointing finding to emerge from reviewing these new developments is that robust evaluations are noticeable by their absence. Any evaluations reported are often on small, heterogeneous samples and lack a comparison or control group. This is not surprising as funding for these activities is difficult to obtain and the practicalities of running an evaluation are challenging. Just determining what is the best comparison group for the intervention puts off many researchers. Lack of such evaluations may go some way to explaining why none of these developments reviewed are commercially available. In order to reassure commercial distributors and practitioners that these interventions are worth investing in for their learners, evaluations are necessary. Hopefully, the next review of IT developments for special education will include such evaluations.

\section{References}

Alaszewski, A. \& Alaszewski, H. (2002) Towards the creative management of risk: perceptions, practices and policies. British Journal of Learning Disabilities, 30, 56-62.

Almack, K., Clegg, J., \& Murphy, E. (2009). Parental negotiations of the moral terrain of risk in relation to young people with learning disabilities. Journal of Community and Applied Social Psychology, 19(4), 286-299. doi: 10.1002/casp.992

Battocchi, A., Ben-Sasson, A., Esposito, G., Gal, E., Pianesi, F., Tomasini, D., et al. (2010). Collaborative puzzle game: a tabletop interface for fostering collaborative skills in children with autism spectrum disorders. Journal of Assistive Technologies, 4(1), 4-13. doi: 10.5042/jat.2010.0040

Brown, D. J., Battersby, S., \& Shopland, N. (2005). Design and evaluation of a flexible travel training environment for use in a supported employment setting. International Journal of Disability and Human Development, 4(3), 251-258.

Brown, D. J., Battersby, S. J., Standen, P. J., \& Anderton, N. (2005). Inclusive design for disability. A prototype switch for use in virtual learning environments. International Journal of Disability and Human Development, 4(2) 103-119. doi: 10.1515/IJDHD.2005.4.2.103 
Brown, D. J., McHugh, D., Standen, P., Evett, L., Shopland, N., \& Battersby, S. (2010). Designing Location based Learning Experiences for People with Intellectual Disabilities and Additional Sensory Impairments, Computers \& Education, 56(1) 11-20. doi: 10.1016/j.compedu.2010.04.014

Brown, D. J., Mclver, E., Standen, P. J., \& Dixon, P. (2008). Can Serious Games Improve Memory Skills in People with ID? Journal of Intellectual Disability Research. 52(8 \& 9), 678.

Brown, D. J., Standen, P. J., Evett, L. Battersby, S. \& Shopland, N. (2010). Designing serious games for people with dual diagnosis: Learning disabilities and sensory impairments. In P. Zemliansky \& D. Wilcox (Eds.), Design and Implementation of Educational Games: Theoretical and Practical Perspectives. Chp. 27, p424-440. Hershey, PA: IGI-Global.

Brown, D. J., Ley, J., Evett, L. \& Standen, P. J. (2011). Can participating in games based learning improve mathematics skills in students with intellectual disabilities. Paper presented at IEEE 1st International Conference on Serious Games and Applications for Health (SeGAH 2011), Braga, Portugal. Retrieved from http://www.proceedings.com/14390.html

Buhler, C. (2001). Empowered participation of users with disabilities in R\&D projects. Int. J. HumanComputer Studies, 55(4), 645-659. doi: 10.1006/ijhc.2001.0489

Burack, J. A., \& Zigler, E. (1990). Intentional and incidental memory in organically mentally retarded, familial retarded, and nonretarded individuals. American Journal on Mental Retardation, 94(5), $532-540$.

Burke, R. V., Andersen, M. N., Bowen, S. L., Howard, M. R., \& Allen, K. D. (2010). Evaluation of two instruction methods to increase employment options for young adults with autism spectrum disorders. Research in Developmental Disabilities, 31(6), 1223-1233.

Clark, A., \& Hirst, M. (1989). Disability in Adulthood: ten-year follow-up of young people with disabilities. Disability, Handicap \& Society, 4(3), 271-283. doi: 10.1080/02674648966780291

Daly-Jones, O., Thomas, C., \& Bevan, N. (1999). Handbook of User-Centred Design. Teddington, England: Serco Usability Services, National Physical Laboratory.

Elgi, E. A., \& Meyers, L. S. (1984). The role of video game playing in adolescent life: is there a reason to be concerned? Bulletin of the Psychonomic Society, 22(4), 309-312.

Fernández López, A., Rodríguez-Fórtiz, M. J., \& Noguera, M. (2009). Designing and Supporting Cooperative and Ubiquitous Learning Systems for People with Special Needs. In R. Meersman, P. Herrero \& T. Dillon (Eds.), On the Move to Meaningful Internet Systems: OTM 2009 Workshops. (Lecture Notes in Computer Science, vol. 5872, pp. 423-432). Heidelberg, Germany: SpringerVerlag. DOI: 10.1007/978-3-642-05290-3_54

Garris, R., Ahlers, R., Driskell, J. E. (2002). Games, motivation and learning. Simulation\& Gaming: An Interdisciplinary Journal of Theory, Practice and Research, 33(4), 43-56. doi: $10.1177 / 1046878102238607$

Gentry, T., Wallace, J., Kvarfordt, C., \& Lynch, K. (2010). Personal digital assistants as cognitive aids for high school students with autism: Results of a community based trial. Journal of Vocational Rehabilitation, 32(2), 101-107. doi: 10.3233/JVR-2010-0499

Gow, L. P., Balla, J., \& Butterfield, E. (1990). The relative efficacy of cognitive and behavioural approaches to instruction in promoting adaptive capacity. In Fraser W. I. (Ed.), Key Issues in Mental Retardation Research (pp. 366-376). London, England: Routledge.

Green, C. S., \& Bavelier, D. (2003). Action video game modifies visual selective attention. Nature, 423(6939), 534-537.

Green, C. S., \& Bavelier, D. (2007). Action video game experience alters the spatial resolution of vision. Psychological Science, 18(1), 88-94. doi: 10.1111/j.1467-9280.2007.01853.x 
Horton, S. (2006). Access by Design: A Guide to Universal Usability for Web Designers. Berkeley, CA: New Riders. Retrieved Apr 27, 2012, from http://universalusability.com

Kintsch, A., \& DePaula, R. (2002, Sep 26). A Framework for the Adoption of Assistive Technology. Paper presented at SWAAAC 2002: Supporting Learning Through Assistive Technology, Winter Park, CO, USA.

Lemoncello, R., Sohlberg, M. M., \& Fickas, S. (2010). How best to orient travellers with acquiredbrain injury: A comparison of three directional prompts. Brain Injury, 24(3), 541-549. doi: 10.3109/02699051003610425

Lilley, C. (2004). A whole school approach to ICT for children with physical disabilities. In L. Florian \& J. Hegarty (Eds.), ICT and Special Educational Needs: A tool for inclusion (pp. 80-95). Maidenhead, England: Open University.

Lindström, J. (2007). New technologies to help people with disabilities and elderly people. In PRW Roe (Ed.), Towards an inclusive future: Impact and wider potential of information and communication technologies (pp. 9-42). Brussels: COST. Retrieved Mar 20, 2012, from http://www.tiresias.org/cost219ter/inclusive_future/inclusive_future_book.pdf

Maguire, M., Kirakowski, J., \& Vereker, N. (1998). RESPECT: User centred requirements handbook (Version 3.3). Teddington, England: RESPECT Consortium. Retrieved Apr 27, 2012, from https://dspace.lboro.ac.uk/dspace-jspui/handle/2134/2651

Naismith, L., Lonsdale, P., Vavoula, G., \& Sharples, M. (2004). Report 11: Literature Review in Mobile Technologies and Learning. NESTA FutureLab Series. Retrieved Mar 20, 2012, from http://elearning.typepad.com/thelearnedman/mobile learning/reports/futurelab review 11.pdf

Nordness, P. D., Haverkost, A., \& Volberding, A. (2011). An Examination of Hand-held Computerassisted Instruction on Subtraction Skills for Second Grade Students with Learning and Behavioral Disabilities. A Journal of Special Education Technology, 26(4), pp. 15-24.

Parette, P., \& Scherer, M. (2004). Assistive Technology Use and Stigma. Education and Training in Developmental Disabilities, 39(3), 217-226.

Pivec, M. (2007). Editorial: Play and learn: potentials of game-based learning. British Journal of Educational Technology, 38(3), 387-393. doi: 10.1111/j.1467-8535.2007.00722.x

Poulson, D. F., \& Waddell, F. N. (2001). USERfit: user centred design in assistive technology. In C. A. Nicholle \& J. Abascal (Eds.), Inclusive Guidelines for Human-Computer Interaction (pp. 143-150). New York, NY: Tailor \& Francis.

Rodríguez-Fórtiz, M. J., González, J. L., Fernández, A., Entrena, M., Hornos, M., Pérez, A., Carrillo, A. \& Barragán, L. (2009). Sc@ut: Developing Adapted Communicators for Special Education. Procedia - Social and Behavioral Sciences, 1(1), 1348-1352. doi: 10.1016/j.sbspro.2009.01.238

Rose, D., \& Strangman, N. (2007). Cognition and learning: Meeting the challenge of individual differences. Universal Access in the Information Society, 5(4), 381-391.

Savidis, A., Grammenos, D., \& Stephanidis, C. (2007). Developing inclusive e-learning and eentertainment to effectively accommodate learning difficulties. Universal Access in the Information Society, 5(4), 401-419. doi: 10.1007/s10209-006-0059-3

Schelhowe, H. S., \& Zare, S. (2009). Intelligent Mobile Interactions: A Learning System for Mentally Disabled People (IMLIS). In C. Stephanidis (Ed.), Universal Access in $\mathrm{HCl}$ (Lecture Notes in Computer Science, LNCS vol. 5614, Part 1, pp. 412-421), Heidelberg, Germany: Springer Verlag.

Sik Lányi, C., Brown, D. J., Standen, P., Lewis, J., \& Butkute, V. (2010). User interface evaluation of serious games for students with intellectual disability. In C. S. Lany, D. J. Brown, P. Standen, J. Lewis, V. Butkute. (Eds.), Computers Helping People with Special Needs (Lecture Notes in 
Computer Science, LNCS vol. 6179, ICCHP 2010, Part 1, pp. 227-334). Heidelberg, Germany: Springer-Verlag Berlin Heidelberg.

Standen, P. J., \& Brown, D. J. (2004). Using virtual environments with pupils with learning disabilities. In L. Florian \& J. Hegarty (Eds.), ICT and Special Educational Needs: a tool for inclusion (pp. 96108). Berkshire, England: Open University Press.

Standen, P. J., \& Brown, D. J. (2005). Virtual reality in the rehabilitation of people with intellectual disabilities: Review. Cyberpsychology \& Behaviour, 8(3), 272-282. doi: 10.1089/cpb.2005.8.272

Standen, P. J., \& Brown, D. J. (2006). Virtual reality and its role in removing the barriers that turn cognitive impairments into intellectual disability. Virtual Reality, 10(3-4), 241-252. doi: 10.1007/s10055-006-0042-6

Standen, P. J., Brown, D. J., Anderton, N., \& Battersby, S. (2006a). Systematic evaluation of current control devices used by people with intellectual disabilities in non-immersive virtual environments. Cyberpsychology \& Behaviour, 9(5), 608-613. doi: 10.1089/cpb.2006.9.608

Standen, P. J., Brown, D. J., Anderton, N., \& Battersby, S. (2006b). Designing a device to navigate in virtual environments for use by people with intellectual disabilities. In P. Sharkey, T. Brooks \& S. Cobb (Eds.), Proceedings of the 6th International Conference on Disability, Virtual Reality and Associated Technologies (pp. 125-131). Reading, England: University of Reading.

Standen, P. J., Rees, F., \& Brown, D. J. (2009). Effect of playing computer games on decision making in people with intellectual disabilities. Journal of Assistive Technologies, 3(2), 6-15. doi: 10.1108/17549450200900011

Strauss, D., Shavelle, D., Anderson, T. W., \& Baumeister, A. (1998). External causes of death among people with developmental disability. American Journal of Epidemiology, 147(9), 855-862.

Ulicsak, M., \& Wright, M. (2010). Serious games in education. Futurelab. Retrieved Mar 30, 2012, from http://archive.futurelab.org.uk/resources/publications-reports-articles/literaturereviews/Literature-Review1788

Van der Meer, L., Kagohara, D., Achmadi, D., Green, V. A., Herrington, C., \& Victoria, J. S. (2011). Teaching functional use of an iPod-based speech-generating device to students with developmental disabilities. Journal of Special Education Technology, 26(3), 1-11.

Van der Molen, M. J., Van Luit J. E. H., Van der Molen, M. W., Klugkist, I., \& Jongmans, M. J. (2010). Effectiveness of a computerised working memory training in adolescents with mild to borderline intellectual disabilities. Journal of Intellectual Disability Research, 54(5), 433-447. doi: 10.1111/j.1365-2788.2010.01285.x

Williamson, B. (2009). Computer games, schools, and young people: A report for educators on using games for learning. Futurelab. Retrieved Apr 25, 2012, from http://archive.futurelab.org.uk/resources/documents/project_reports/becta/Games_and_Learni ng_educators_report.pdf 